\title{
Ratcheting and recovery of adhesively bonded joints under tensile cyclic loading
}

\author{
Yi Chen ${ }^{1} \cdot$ Lloyd V. Smith ${ }^{1}$ (ID
}

Received: 10 July 2021 / Accepted: 7 December 2021 / Published online: 20 December 2021

(c) The Author(s) 2021

\begin{abstract}
Polymers in general, and adhesives in particular, can exhibit nonlinear viscoelasticviscoplastic response. Prior work has shown that this complex behavior can be described using analytical models, which provided good agreement with measured creep and recovery response. Under cyclic loading, however, some adhesives exhibit a temporal response different from what would be expected from their creep behavior. Ratcheting describes the accumulation of deformation from cyclic loading. The failure surfaces of adhesives subjected to creep and cyclic loads provide evidence of failure modes that depend on the loading history, suggesting a cause for the change in temporal response. The following considers two approaches to describe the ratcheting behavior of adhesives. Given the reduced time dependence, the first approach involved a nonlinear viscoelastic-plastic model. The second approach used a nonlinear viscoelastic-viscoplastic model, calibrated from the cyclic response, rather than the creep response. While both models showed good agreement with experiment for long exposure to cyclic loading, only the viscoelastic-viscoplastic model agreed with experiment for both short and long loading histories.
\end{abstract}

Keywords Adhesives $\cdot$ Ratcheting $\cdot$ Viscoelastic $\cdot$ Viscoplastic

\section{Introduction}

Adhesives can provide prolonged product life with reduced maintenance and are, therefore, widely used in the aerospace industry. Adhesive joints are often subjected to cyclic loadings (Broughton et al. 1999). Ratcheting is a phenomenon where the strain accumulates progressively with each cycle. Understanding and predicting adhesive-ratcheting behavior is important for designing and optimizing adhesively bonded joints since ratcheting can lead to debonding and failure (Shariati et al. 2012).

Ratcheting of polymeric materials is complicated since the strain accumulation depends on the material and type of loading. Shen et al. (2004) studied the effect of mean stress, amplitude, and loading rate on an epoxy resin's response to uniaxial cyclic tests. They observed that the ratcheting strain did not introduce damage or influence the material's fatigue

L.V. Smith

lvsmith@wsu.edu

1 The School of Mechanical and Materials Engineering, Washington State University, Sloan Hall, 405 NE Spokane Street, Pullman, WA 99164, USA 
life (Tao and Xia 2007). Xia et al. (2005) proposed a viscoelastic model where a loading and an unloading modulus described the hysteresis loop. Zhang et al. (2019) did similar uniaxial tension cyclic experiments on adhesively bonded hollow cylindrical butt joints and found that the fatigue life decreased with increased mean stress, amplitude and loading rate. Lin et al. studied the effect of stress history on plastic deformation in an anisotropic conductive adhesive film bonded joint (Lin et al. 2011). High magnitude cyclic stress restrained plastic deformation under subsequent lower magnitude stress, while the prior high loading rate increased the deformation of subsequent cycles with a lower loading rate. Da Costa Mattos and Martins (2013) observed hysteresis that led to ratcheting when an epoxy was subjected to cyclic loading with increasing amplitude. The phenomenon was due to kinematic hardening. Shakedown, a stable hysteresis loop, was also observed after a few cycles. Their phenomenological elastic-plastic model was able to describe this plastic cyclic behavior. Mattos's group used similar methods and experiments to study the ratcheting behavior of two polymeric materials (da Costa Mattos et al. 2017; Motta et al. 2018, 2019), where ratedependent strain hardening was observed. The elastic-viscoplastic model was based on the classic Lemaitre-Chaboche model where kinematic hardening showed good agreement with cyclic and monotonic experiments. However, this model, as well as the phenomenological elastic-plastic model (Da Costa Mattos and Martins 2013), were one dimensional.

Lap shear joints have a complex stress distribution and deformation even under simple tensile loads due to bending and rotation. Lap joints are often modeled as a planestrain/stress problem. Li and Lee-Sullivan (2001) considered the effects of plane strain/stress and boundary conditions from adherends on the stress distribution. They did not find a significant difference between these two boundary conditions. Describing adhesives as elastoplastic is commonly conducted to investigate the influence of adherend material or the joint geometry on the performance of lap shear joints (Broughton 1999; Fessel et al. 2007; Sayman 2012). To account for the nonlinear time-dependent stress/strain responses, viscoelastic and viscoplastic models have been employed. Groth (1990) studied the stress distribution across the overlap area using viscoelastic-viscoplastic models. Using a similar rheological model, Zehsaz et al. (2014) discussed the influence of adhesive thickness and fillet on the creep behavior for double lap joints. The model had good agreement with experiment and showed that adhesive thickness had a negligible effect, while the adhesive fillet would increase creep life. Pandey and Narasimhan (2001) proposed a three-dimensional (3D) elasticviscoplastic model for the adhesive in a single lap joint considering geometric nonlinearity. The viscoplastic analysis led to less stress at the overlap ends than an elastic solution. The foregoing considered lap shear joints loaded monotonically or under creep. There is limited analysis of lap shear joints subjected to cyclic loading and recovery.

The aim of this paper is to describe the ratcheting-recovery behavior of adhesives. Using finite elements, a viscoelastic-plastic model and a nonlinear viscoelastic-viscoplastic model are proposed. The models are used to predict adhesive response to cyclic tensile loading and are compared with experiment.

\section{Experiment and finite-element method}

The ratcheting and recovery of adhesive films were investigated by a series of shear tests on scarf and lap shear joints.

\subsection{Test coupons}

Figure 1 shows the geometries of scarf and lap shear joints, where both were $25 \mathrm{~mm}$ wide. A "toughened" (Hysol EA9696) and "standard" (Cytec FM300-2) adhesive film were bonded 


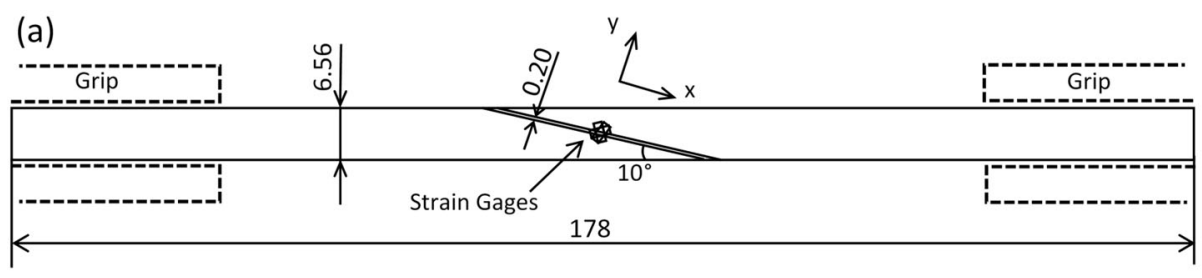

(b)
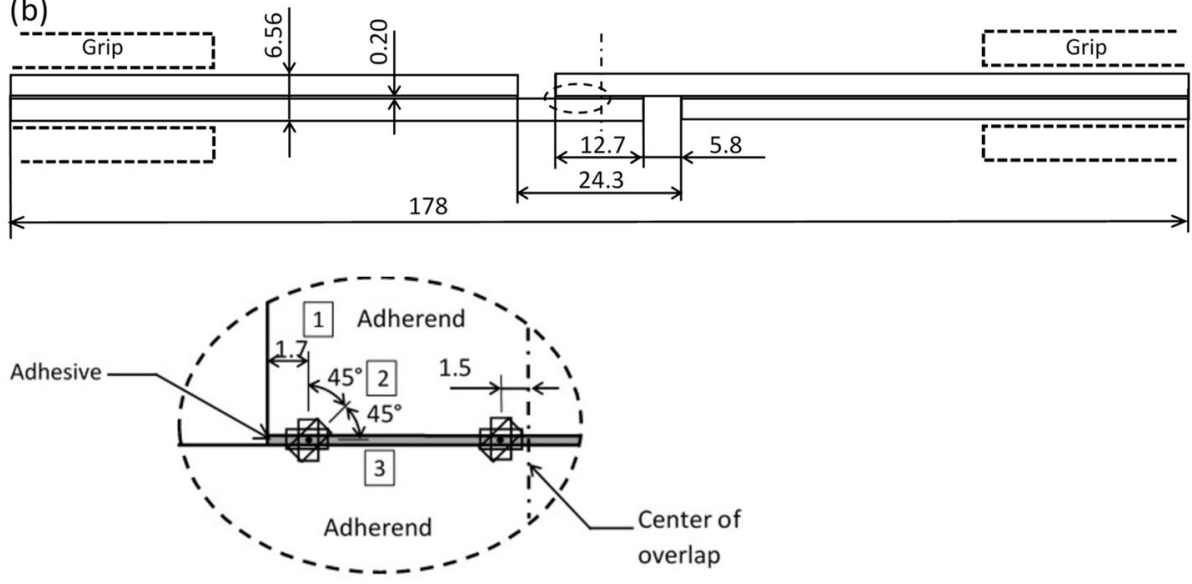

Fig. 1 Geometry and bonded strain gages for (a) scarf joint and (b) lap shear joint. All dimensions are in mm

in a 10-degree scarf joint, while only the toughened adhesive was considered for lap shear joints (ASTM D3165-07 2014). For both coupons, the adherends were made of 2024 aluminum plates that were phosphoric anodized and primed before bonding. The toughened and standard adhesive bonding occurred at $120^{\circ} \mathrm{C}$ for 105 and $90 \mathrm{~min}$, respectively. More details about the pretreatment and curing process can be found elsewhere (Krause and Smith 2021). Ratcheting tests were conducted using a servohydraulic load frame with grips clamping both ends of the joints. Load was applied as a sine wave where the ratio of the minimum to the maximum stress was defined as R.

\subsection{Strain measurement}

The adhesive strain was measured using a 45-degree rectangular stacked rosette strain gage (Micro-Measurements 062WW) with a sensing area of $1.27 \mathrm{~mm} \times 1.57 \mathrm{~mm}$. The strain distribution along the bond line of scarf joints is relatively uniform (He et al. 2010). The strain gage for scarf joints was bonded over the center of the bond line, as shown in Fig. 1a. The strain distribution along the bond line for a lap shear joint is not uniform (Pandey et al. 1999). Strain gages of lap shear joints were placed near the edge and center of the overlap as shown in Fig. 1b. The gages parallel and perpendicular to the bond line were identified as gage 3 and 1, respectively. Gage 2 was at 45 -degrees to the bondline. 
Fig. 2 Shear strain-stress curves from strain gages and DIC

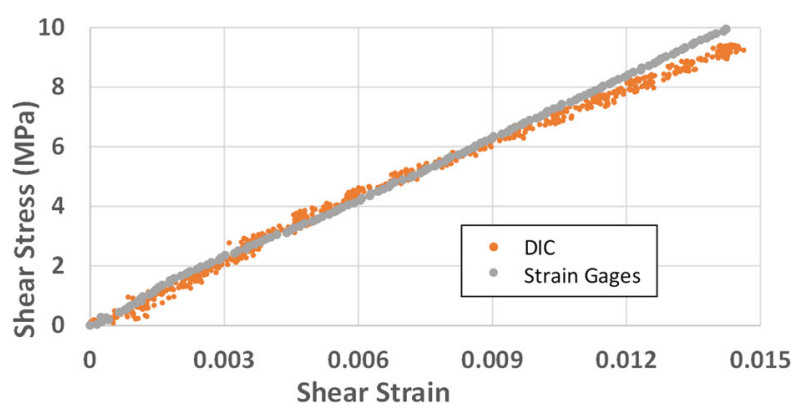

The strain gage's sensing area covered both adherend and adhesive. For gages 1 and 2, the total measured strain, $\varepsilon_{1}$ and $\varepsilon_{2}$, can be written as,

$$
\begin{gathered}
\varepsilon_{1}=\frac{\Delta L_{s}+\Delta L_{r}}{L}=\frac{t\left(1+\beta_{1}\right) \Delta L_{s}}{t L}=\frac{t\left(1+\beta_{1}\right)}{L} \varepsilon_{1}^{\prime} \\
\varepsilon_{2}=\frac{\Delta L_{s}+\Delta L_{r}}{L}=\frac{t\left(1+\beta_{2}\right) \Delta L_{s}}{L \cos \left(45^{\circ}\right) t / \cos \left(45^{\circ}\right)}=\frac{t\left(1+\beta_{2}\right)}{L \cos \left(45^{\circ}\right)} \varepsilon_{2}^{\prime}
\end{gathered}
$$

where $\varepsilon_{1}^{\prime}$ and $\varepsilon_{2}^{\prime}$ represent the adhesive strain for gages 1 and 2 , respectively. $\Delta L_{s}$ and $\Delta L_{r}$ denote the length change along the strain gage direction for the adhesive and adherend, respectively. $L$ is the strain gage's sensing length. $t$ is the adhesive thickness. $\beta_{1}$ and $\beta_{2}$ were obtained approximately by finite-element analysis by considering the adhesive as elastoplastic (an assumption that is widely used for adhesives Sayman 2012; Mardani et al. 2020). Von Mises yielding with kinematic hardening was employed and the plastic parameters are discussed below.

For gage 3, finite-element analysis showed the strain of the adhesive was close to that of the adherend. The adhesive strain was therefore defined by

$$
\varepsilon_{3}=\varepsilon_{3}^{\prime}
$$

The adhesive strain for each gage was obtained from Eqs. (1)-(3). The shear strain of the adhesive was calculated using (Micro-Measurements 2008)

$$
\gamma_{x y}=2 \varepsilon_{2}^{\prime}-\varepsilon_{1}^{\prime}-\varepsilon_{3}^{\prime}
$$

The scarf joints with the toughened adhesive were loaded at $74 \mathrm{~N} / \mathrm{s}$ and the strain was measured using strain gages and digital image correlation (DIC) (Mohapatra and Smith 2019a). The shear strain-stress responses of the adhesive are compared in Fig. 2, showing good agreement. (The shear stress in Fig. 2 was the average stress in the adhesive.)

\subsection{Finite-element model description}

The scarf and lap shear joints were meshed using the preprocessor in ABAQUS 2016, as shown in Fig. 3. 4-node bilinear, reduced integration with hourglass control plane-strain elements (CPE4R) were employed for the lap shear joint and most of the scarf joint. 3-node linear plane strain elements (CPE3) were used for the wedge-shaped elements near the edge of bond line of the scarf joint. Under guidance from a convergence study, the adhesive was divided into four layers through the thickness (Chen and Smith 2021). Both ends of the joint 
(a)

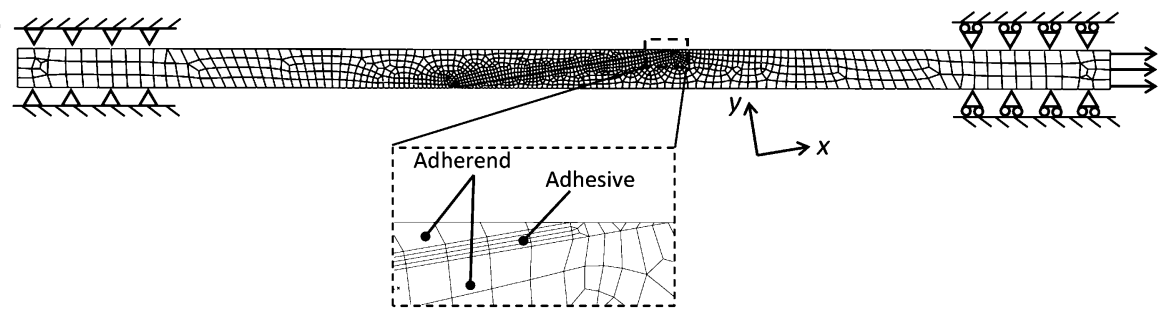

(b)

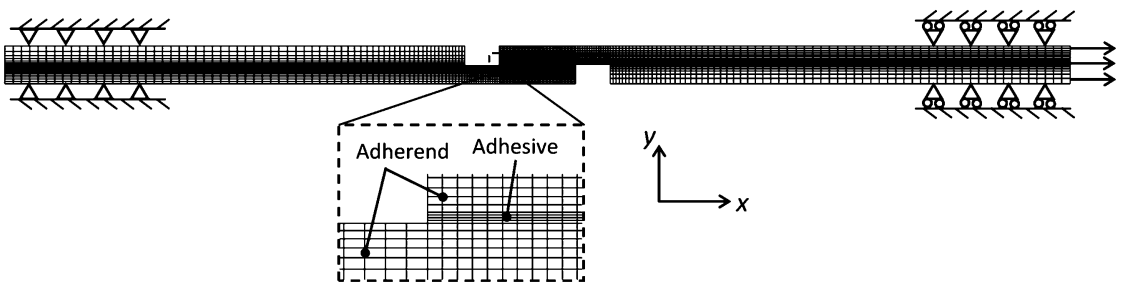

Fig. 3 Mesh and boundary conditions for the (a) scarf and (b) lap shear joint

were supported to represent the load-frame grips. A pressure load was applied on the freeend surface. The adherend was modeled as a linear elastic material with a modulus of 73 $\mathrm{GPa}$ and a Poisson's ratio of 0.33 .

\section{Ratcheting recovery of scarf and lap shear joints}

As described in detail elsewhere (Chen and Smith 2021) a three-dimensional viscoelasticviscoplastic model (VE-VP) developed from creep-recovery measurements, has shown good agreement with adhesives under a series of creep-loading environments. The model combined a modified Schapery nonlinear viscoelastic model (Lai and Bakker 1996) with Perzyna's viscoplastic model (Perzyna 1966) using von Mises yielding and nonlinear kinematic hardening (both of which are described below). This model was compared with cyclically loaded scarf joints and lap shear joints, as shown in Fig. 4 and Fig. 5, respectively.

\subsection{Comparison between VE-VP and experiment}

The scarf joints were cyclically loaded at three frequencies, $0.5,3$ and $5 \mathrm{~Hz}$, with $\mathrm{R}=0.1$. The maximum shear stress was $50 \%$ of the adhesive's shear strength (USS). The specimens were run for 10000 cycles at each frequency before load removal and recovery (Krause and Smith 2021). Note that Fig. 4 presents strain as a function of the loading cycles, so that lower-frequency tests have a longer cumulative load duration, and therefore a higher peak strain. There is considerable variation in the experimental data, so that the strain responses from the different frequencies overlap each other. It is, nevertheless, apparent that the toughened adhesive (Fig. 4a) has more time dependence and permanent strain than the standard adhesive (Fig. 4b). Furthermore, while the standard adhesive shows generally good agreement with the VE-VP model, the toughened adhesive departs from the model in significant ways. The VE-VP peak strain and permanent strain show more time dependence that was observed experimentally. 

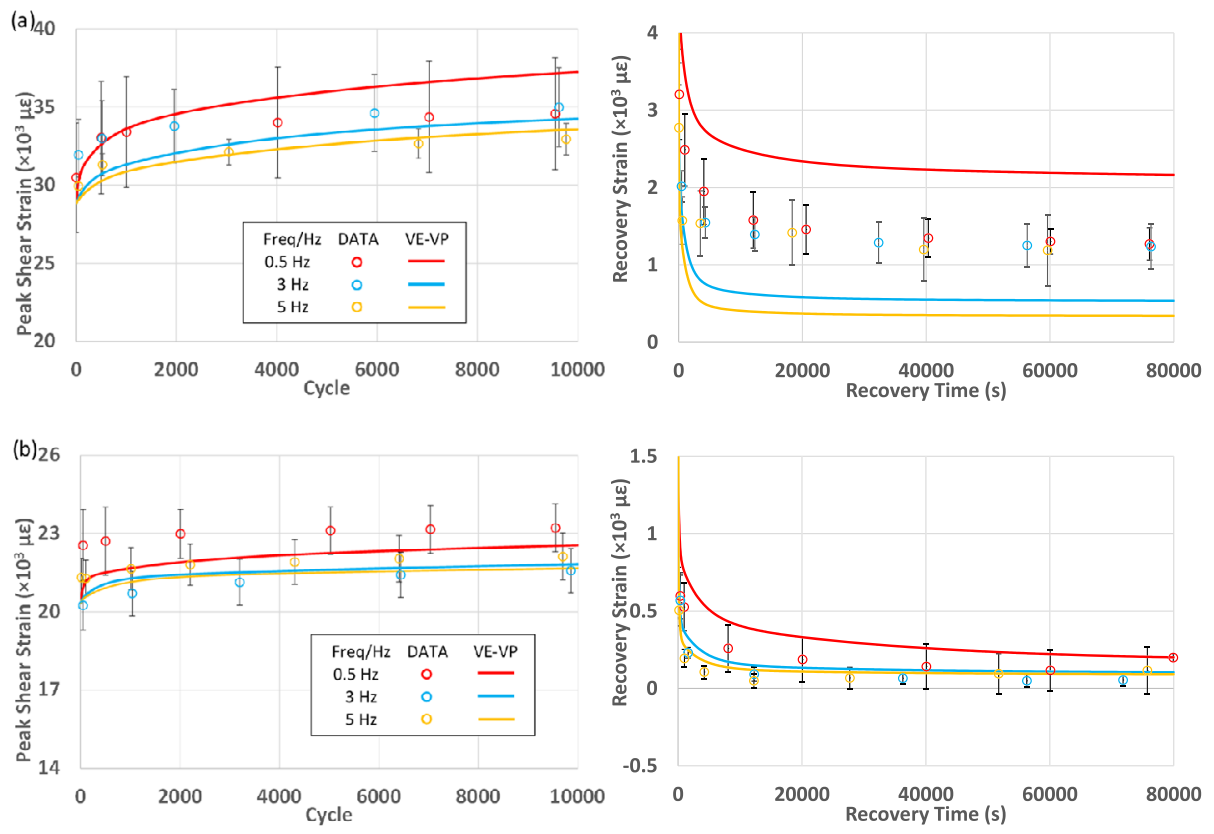

Fig. 4 Comparison of the ratcheting-recovery responses between the creep-based model and experiment for a (a) toughened and (b) standard adhesive within scarf joints. Error bars correspond to one standard deviation
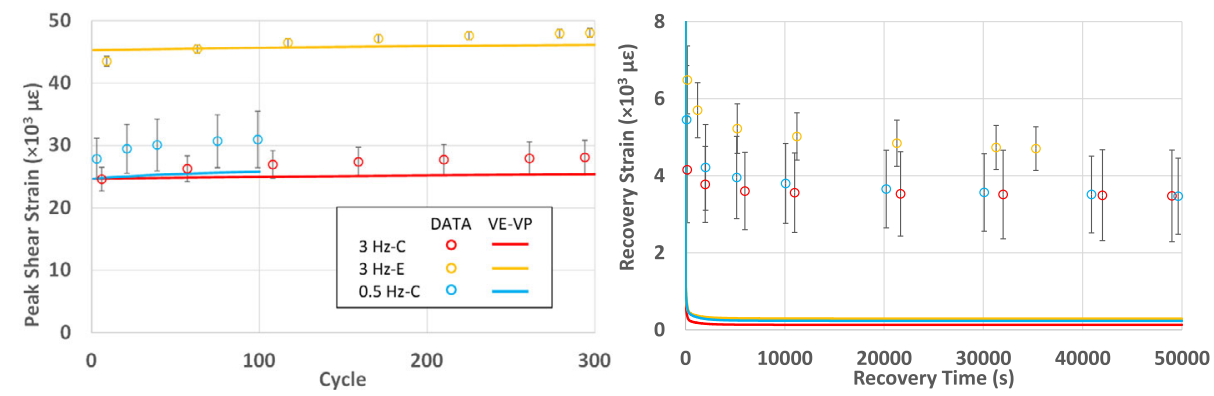

Fig. 5 Comparison of the ratcheting-recovery response of the toughened adhesive near the center (C) and edge $(\mathrm{E})$ of the overlap between the model and experiment for lap shear joints. Error bars correspond to one standard deviation

The scarf joint results presented above describe a nearly pure adhesive shear state. Ratcheting experiments with the toughened adhesive were conducted on lap shear joints to consider a more complex stress state. Test coupons were bonded with the toughened adhesive and cyclically loaded at $\mathrm{R}=0.1$ and $50 \%$ USS. The joints were loaded at two frequencies, $0.5 \mathrm{~Hz}$ with strain measurement near the center of the gage section, and at $3 \mathrm{~Hz}$ with strain measured near the center and edge of the gage section. The coupons were run for 100 and 300 cycles at 0.5 and $3 \mathrm{~Hz}$, respectively, to avoid failure by the stress concentration on the edge of the overlap. Figure 5 shows the comparison between the VE-VP model and experiment. Measured strain was sensitive to the position where the strain near the edge was larger than that near the center. Neither the experiment nor the VE-VP model showed a 
Fig. 6 Residual strain under varying cyclic loadings, illustrating viscoplastic behavior at short time scales and the inability of models based on creep response to describe cyclic behavior

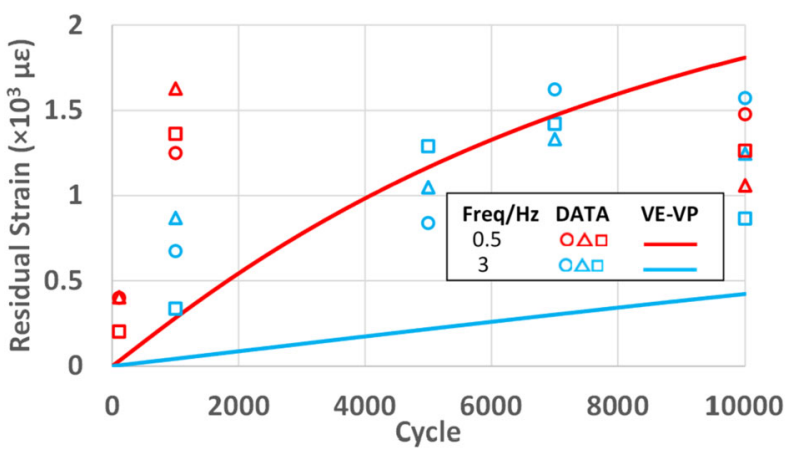

significant temporal effect between different frequencies since the load durations at 0.5 and $3 \mathrm{~Hz}$ were similar. However, the model showed negligible permanent strain, departing from experiment.

\subsection{Temporal effect of the toughened adhesive}

The cyclic tests presented in Fig. 4a showed little evidence of viscoplastic behavior, but all were conducted for 10000 cycles. Tests at varying frequencies and loading cycles were conducted to determine if viscoplastic behavior could be observed at shorter time scales for the toughened adhesive. The adhesive residual strain is plotted as a function of loading cycle in Fig. 6. Here, and in the following, residual strain refers to the plastic strain and the small amount of time-dependent strain after $80 \mathrm{ks}$ of recovery. At $0.5 \mathrm{~Hz}$, the residual strain increased by a factor of five from 100 to 1000 cycles. At $3 \mathrm{~Hz}$, the residual strain doubled from 1000 to 10000 cycles. A saturation of approximately 1300 microstrain was noted at 1000 cycles for $0.5 \mathrm{~Hz}$ and 7000 cycles for $3 \mathrm{~Hz}$. The predicted viscoplastic strain (solid lines) showed more time dependence but less residual strain at short time scales than was observed experimentally. The discrepancy between experiment and the model (that was developed from creep response) suggests that viscoplastic behavior persists in the toughened adhesive during cyclic loading, but at a different scale than occurs under creep loading (Chen and Smith 2021). As the residual strain corresponding to the viscoplastic deformation was associated with damage and failure, the failure surfaces of scarf joints were investigated.

Figure $7 \mathrm{a}$ and $\mathrm{c}$ show the failure surfaces from failed joints subjected to cyclic reversed loading at $3 \mathrm{~Hz}$ and 50\% USS for the toughened and standard adhesives, respectively. Figure $7 \mathrm{~b}$ and depict the failure surfaces of joints failed from creep at $80 \%$ and $93 \%$ USS for the toughened and standard adhesive, respectively. The voids and randomly dispersed carriers, which would influence failure (Da Silva et al. 2004), were observed in all the pictures. For the toughened adhesive, the failure surface from cyclic loading (Fig. 7a) and creep (Fig. 7b) exhibited different features. The former showed cracks and river lines indicating crack initiation and propagation (Teixeira de Freitas and Sinke 2015) through or surrounding voids radially, while the latter had little evidence of cracks or river lines around voids. The phenomenon in Fig. 4a could be attributed to the stress concentrations surrounding the voids. Moreover, voids helped propagate and accelerate the failure under cyclic loading, resulting in a larger residual strain at 3 and $5 \mathrm{~Hz}$ than the prediction using the parameters from creep tests, as shown in Fig. 4a. For the standard adhesive, the failure surfaces (Figs. 7c and d) were similar, and both showed ridges rather than significant cracks. These similar failure mechanisms explain the agreement of the standard adhesive with experiment under cyclic load using parameters from the creep test in Fig. $4 \mathrm{~b}$. 

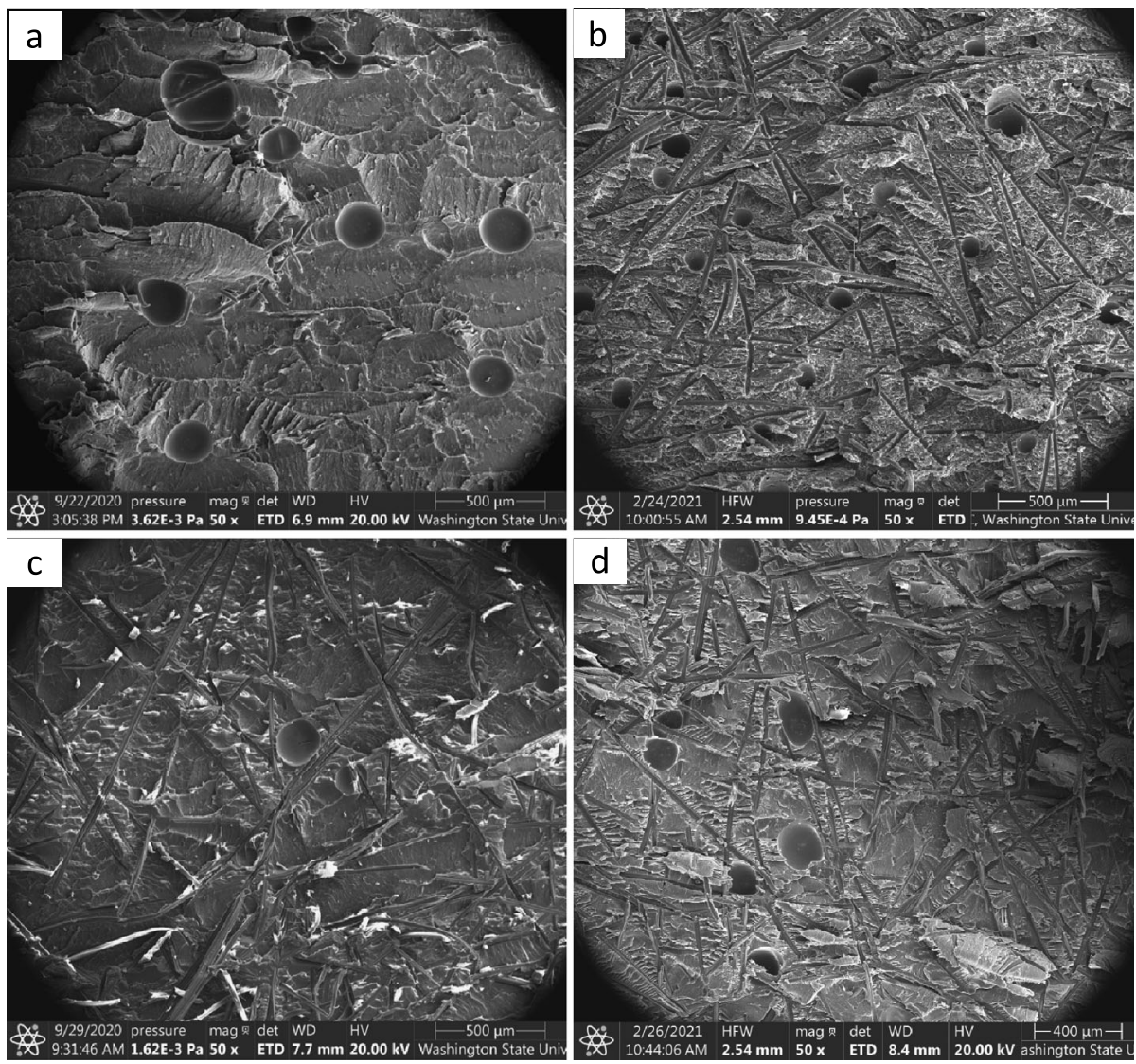

Fig. 7 SEM images of failure surface under cyclic loadings for (a) the toughened and (c) standard adhesive, and under creep loadings for (b) the toughened and (d) standard adhesive

To account for the observed reduced time dependence of the toughened adhesive under cyclic loading, two approaches are compared in the following. The viscoplastic parameters of the VE-VP model were modified by fitting them to the residual strain after cyclic loading; and a nonlinear viscoelastic-plastic model (VE-P) was developed. Since the VE-VP model showed good agreement under creep and cyclic loading for the standard adhesive, the following considers only the response of the toughened adhesive.

\section{Viscoelastic-plastic model}

\subsection{Constitutive model}

Assuming that viscoelastic and plastic deformation are fully uncoupled, the total strain may be described as,

$$
\varepsilon_{i j}^{t o t}=\varepsilon_{i j}^{v e}+\varepsilon_{i j}^{p}
$$


where the superscripts tot, ve and $p$ denote total, viscoelastic and plastic components, respectively. Here, the viscoelastic strain is recoverable while the plastic strain is unrecoverable. The viscoelastic component is the same as that in the viscoelastic-viscoplastic model using the modified Schapery's nonlinear viscoelastic model (Lai and Bakker 1996) consisting of the hydrostatic and deviatoric parts:

$$
\begin{aligned}
\varepsilon_{i j}^{v e, t}= & e_{i j}^{v e, t}+\frac{1}{3} \varepsilon_{k k}^{v e, t} \delta_{i j} \\
= & \frac{1}{2} g_{0}^{t} J_{0} S_{i j}^{t}+\frac{1}{2} g_{1}^{t} \int_{0}^{t} \Delta J^{\psi^{t}-\psi^{\tau}} \frac{d\left(g_{2}^{\tau} S_{i j}^{\tau}\right)}{d \tau} d \tau \\
& +\frac{1}{3}\left(\frac{1}{3} g_{0}^{t} B_{0} \sigma_{k k}^{t} \delta_{i j}+\frac{1}{3} g_{1}^{t} \int_{0}^{t} \Delta B^{\psi^{t}-\psi^{\tau}} \frac{d\left(g_{2}^{\tau} \sigma_{k k}^{\tau}\right)}{d \tau} d \tau \delta_{i j}\right)
\end{aligned}
$$

where $\delta_{i j}$ is the Kronecker delta. $e_{i j}^{v e, t}, \varepsilon_{k k}^{v e, t}$ and $S_{i j}^{t}$ are the deviatoric strain, volumetric strain and deviatoric stress at the current time $t$, respectively. $\psi^{t}$ is the effective time given by

$$
\psi^{t}=\frac{t}{a}
$$

In Eqs. (6) and (7), $a, g_{0}, g_{1}$ and $g_{2}$ are nonlinear parameters dependent on the current stress, $\sigma_{i j}^{t}$, and temperature. However, temperature effects were not considered here.

$J_{0}$ and $B_{0}$ are the instantaneous shear and bulk compliance, respectively. Similarly, $\Delta J^{\psi^{t}}$ and $\Delta B^{\psi^{t}}$ are the transient shear and bulk compliance, respectively, which are expressed as functions of a five-term Prony series:

$$
\begin{aligned}
& \Delta J^{\psi^{t}}=2(1+v) \sum_{n=1}^{5} D_{n}\left(1-\exp \left(-\lambda_{n} \psi^{t}\right)\right) \\
& \Delta B^{\psi^{t}}=3(1-2 v) \sum_{n=1}^{5} D_{n}\left(1-\exp \left(-\lambda_{n} \psi^{t}\right)\right)
\end{aligned}
$$

where $v$ is the Poisson's ratio and assumed to be constant. $D_{n}$ and $\lambda_{n}$ are the $n$th constant and retardation time of the Prony series, respectively.

As observed elsewhere for the adhesives considered here (Mohapatra and Smith 2019b, 2021), the plastic component in Eq. (5) can be described by the von Mises yield criterion with nonlinear kinematic hardening, such that

$$
f=\sqrt{\frac{3}{2}\left(S_{i j}^{t}-\alpha_{i j}^{t}\right)\left(S_{i j}^{t}-\alpha_{i j}^{t}\right)}-\sigma_{y}^{0}
$$

The kinematic hardening describes the movement of the yield surface through the deviatoric backstress tensor, $\alpha_{i j}^{t}$, which can be defined as the sum of several backstress components. Here, the backstress tensor is presented by two components, or

$$
\alpha_{i j}^{t}=\alpha_{i j}^{1, t}+\alpha_{i j}^{2, t}
$$




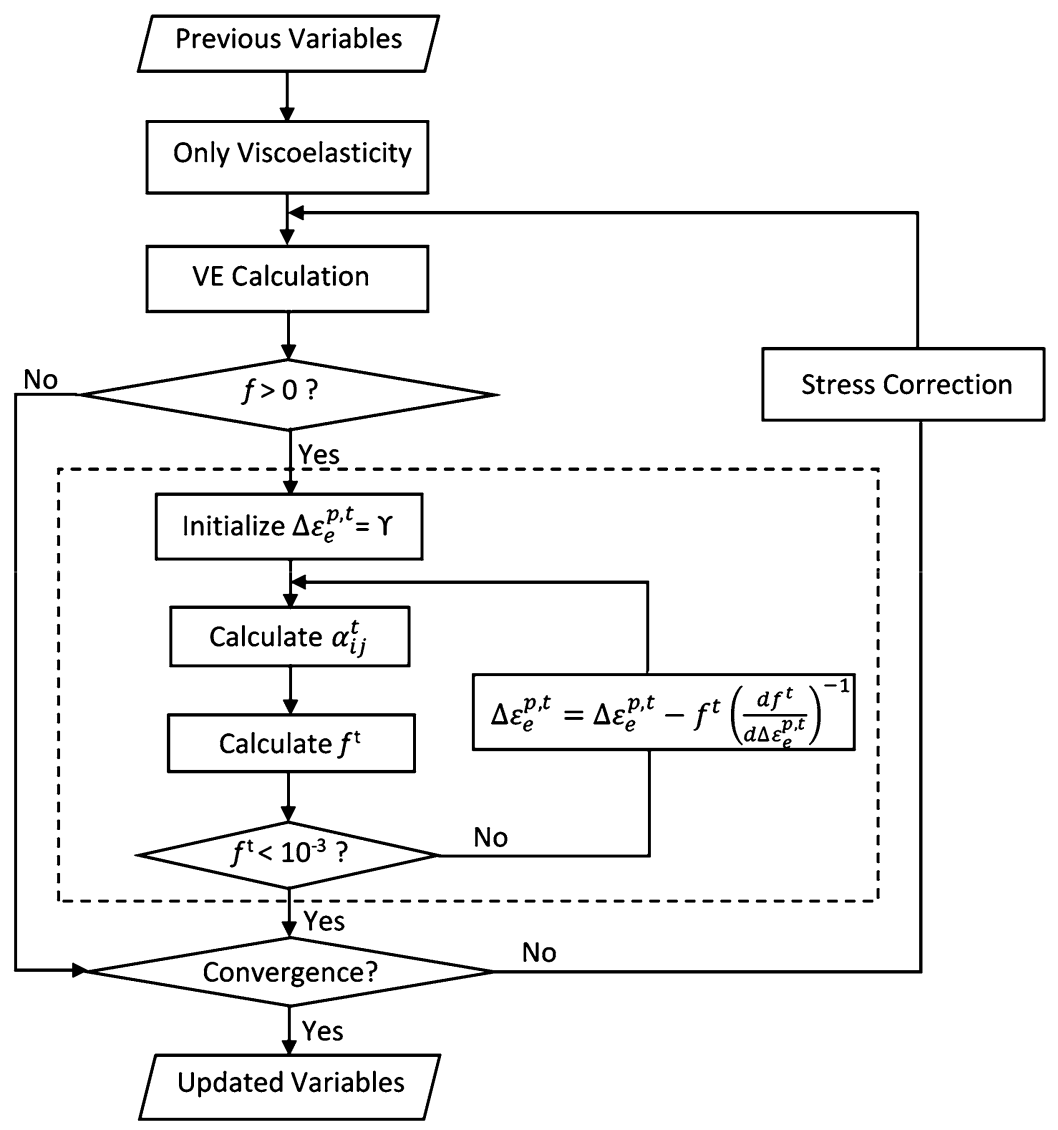

Fig. 8 Flowchart of the viscoelastic-viscoplastic system

The evolution law of each component is defined from the Armstrong-Frederick model (Frederick and Armstrong 2007):

$$
\dot{\alpha}_{i j}^{m, t}=\frac{2}{3} C^{m} \dot{\varepsilon}_{i j}^{p}-\kappa^{m} \alpha_{i j}^{m, t} \dot{\varepsilon}_{e}^{p}=\frac{C^{m}}{\sigma_{y}^{0}}\left(S_{i j}^{t}-\alpha_{i j}^{m, t}\right) \dot{\varepsilon}_{e}^{p}-\kappa^{m} \alpha_{i j}^{m, t} \dot{\varepsilon}_{e}^{p}, \quad(m=1,2)
$$

where $C$ and $\kappa$ are the hardening parameters. $\dot{\varepsilon}_{e}^{p, t}$ is the rate of the effective plastic strain defined by

$$
\dot{\varepsilon}_{e}^{p, t}=\sqrt{\frac{2}{3} \dot{\varepsilon}_{i j}^{p, t} \dot{\varepsilon}_{i j}^{p, t}}
$$

\subsection{Numerical implementation}

The VE-P constitutive model was implemented into ABAQUS using a UMAT with an iterative scheme for the stress correction in Fig. 8. The viscoelasticity formulation can be found elsewhere (Chen and Smith 2021). Newton's iteration was employed for the plastic 
calculation, as shown in the dashed square in Fig. 8. Plasticity was activated when the yield function was greater than zero. At the beginning of each iteration of the whole system, the effective plastic-strain increment, $\Delta \varepsilon_{e}^{p, t}$, is initialized as a constant $\Upsilon$. The deviatoric backstress components are updated by the backward-Euler integration method and Eq. (12), such that

$$
\begin{gathered}
\alpha_{i j}^{1, t}=\left[\alpha_{i j}^{1, t-\Delta t}+\frac{C^{1}}{\sigma_{y}^{0}} \Delta \varepsilon_{e}^{p, t}\left(S_{i j}^{t}-\alpha_{i j}^{2, t}\right)\right] / A^{1} \\
\alpha_{i j}^{2, t}=\left\{\alpha_{i j}^{2, t-\Delta t}+\frac{C^{2}}{\sigma_{y}^{0}} \Delta \varepsilon_{e}^{p, t}\left[\left(1-\frac{C^{1}}{A^{1} \sigma_{y}^{0}} \Delta \varepsilon_{e}^{p, t}\right) S_{i j}^{t}-\frac{\alpha_{i j}^{1, t-\Delta t}}{A^{1}}\right]\right\} \\
/\left[A^{2}-\frac{C^{1} C^{2}}{A^{1}}\left(\frac{\Delta \varepsilon_{e}^{p, t}}{\sigma_{y}^{0}}\right)^{2}\right] \\
A^{i}=1+\frac{C^{i}}{\sigma_{y}^{0}} \Delta \varepsilon_{e}^{p, t}+\kappa^{i} \Delta \varepsilon_{e}^{p, t},(i=1,2)
\end{gathered}
$$

where the superscripts $t$ and $(t-\Delta t)$ represent the current and previous time increment. Subsequently, the yield function $f^{\mathrm{t}}$ is updated by Eqs. (10) and (12).

Once $f^{t}$ approaches zero, namely $f^{t}<10^{-3}$, the iteration converges. Otherwise, the effective strain increment was corrected by,

$$
\Delta \varepsilon_{e}^{p, t}=\Delta \varepsilon_{e}^{p, t}-f^{t}\left(\frac{d f^{t}}{d \Delta \varepsilon_{e}^{p, t}}\right)^{-1}=\Delta \varepsilon_{e}^{p, t}-f^{t}\left(\frac{\partial f^{t}}{\partial S_{i j}^{t}} \frac{d S_{i j}^{t}}{d \Delta \varepsilon_{e}^{p, t}}+\frac{\partial f^{t}}{\partial \alpha_{i j}^{t}} \frac{d \alpha_{i j}^{t}}{d \Delta \varepsilon_{e}^{p, t}}\right)^{-1}
$$

From Eq. (10), it is easily obtained that

$$
\frac{\partial f^{t}}{\partial S_{i j}^{t}}=-\frac{\partial f^{t}}{\partial \alpha_{i j}^{t}}=\frac{3}{2 \sigma_{y}^{0}}\left(S_{i j}^{t}-\alpha_{i j}^{t}\right)
$$

According to the consistency condition, $d f=0$, for the plastic criterion, $d f$ is written as

$$
d f^{t}=\frac{\partial f^{t}}{\partial S_{i j}^{t}} d S_{i j}^{t}+\frac{\partial f^{t}}{\partial \alpha_{i j}^{t}} d \alpha_{i j}^{t}=\frac{3}{2 \sigma_{y}^{0}}\left(S_{i j}^{t}-\alpha_{i j}^{t}\right)\left(d S_{i j}^{t}-d \alpha_{i j}^{t}\right)=0
$$

The relation between $d S_{i j}^{t}$ and $d \varepsilon_{e}^{p, t}$ is obtained by replacing $d \alpha_{i j}^{t}$ with Eqs. (14) and (15):

$$
\left(S_{i j}^{t}-\alpha_{i j}^{t}\right) d S_{i j}^{t}=\left[\frac{2}{3} \sigma_{y}^{0}\left(C^{1}+C^{2}\right)-\left(S_{i j}^{t}-\alpha_{i j}^{t}\right)\left(\kappa^{1} \alpha_{i j}^{1, t}+\kappa^{2} \alpha_{i j}^{2, t}\right)\right] d \varepsilon_{e}^{p, t}
$$

Subsequently, the derivative of the deviatoric stress with respect to the effective strain in Eq. (17) can be obtained.

The derivative of the backstress with respect to the effective strain is given by the sum of each backstress component:

$$
\frac{d \alpha_{i j}^{t}}{d \Delta \varepsilon_{e}^{p, t}}=\frac{d \alpha_{i j}^{1, t}}{d \Delta \varepsilon_{e}^{p, t}}+\frac{d \alpha_{i j}^{2, t}}{d \Delta \varepsilon_{e}^{p, t}}
$$


where,

$$
\begin{aligned}
& \frac{d \alpha_{i j}^{1, t}}{d \Delta \varepsilon_{e}^{p, t}}=\frac{C^{1}}{A^{1} \sigma_{y}^{0}}\left[S_{i j}^{t}-\alpha_{i j}^{2, t}+\Delta \varepsilon_{e}^{p, t}\left(\frac{d S_{i j}^{t}}{d \Delta \varepsilon_{e}^{p, t}}-\frac{d \alpha_{i j}^{2, t}}{d \Delta \varepsilon_{e}^{p, t}}\right)\right] \\
& -\frac{C^{1}+\sigma_{y}^{0} \kappa^{1}}{\sigma_{y}^{0}\left(A^{1}\right)^{2}}\left(\alpha_{i j}^{1, t-\Delta t}+\frac{C^{1} \Delta \varepsilon_{e}^{p, t}}{\sigma_{y}^{0}}\left(S_{i j}^{t}-\alpha_{i j}^{2, t}\right)\right) \\
& \frac{d \alpha_{i j}^{2, t}}{d \Delta \varepsilon_{e}^{p, t}}=\frac{1}{B}\left\{\frac{C^{2}}{\sigma_{y}^{0}}\left[S_{i j}^{t}\left(1-\frac{2 C^{1}}{A^{1} \sigma_{y}^{0}} \Delta \varepsilon_{e}^{p, t}\right)-\frac{\alpha_{i j}^{1, t-\Delta t}}{A^{1}}\right]+C^{1} C^{2}\left(\frac{\Delta \varepsilon_{e}^{p, t}}{A^{1} \sigma_{y}^{0}}\right)^{2}\right. \\
& \left.\times\left[\left(S_{i j}^{t}+\frac{\sigma_{y}^{0}}{C^{1} \Delta \varepsilon_{e}^{p, t}} \alpha_{i j}^{1, t-\Delta t}\right) \frac{d A^{1}}{d \Delta \varepsilon_{e}^{p, t}}-A^{1} \frac{d S_{i j}^{t}}{d \Delta \varepsilon_{e}^{p, t}}\right]+C^{2} \frac{\Delta \varepsilon_{e}^{p, t}}{\sigma_{y}^{0}} \frac{d S_{i j}^{t}}{d \Delta \varepsilon_{e}^{p, t}}\right\} \\
& -\frac{1}{B^{2}}\left\{\alpha_{i j}^{2, t-\Delta t}+\frac{C^{2}}{\sigma_{y}^{0}} \Delta \varepsilon_{e}^{p, t}\left[\left(1-\frac{C^{1}}{A^{1} \sigma_{y}^{0}} \Delta \varepsilon_{e}^{p, t}\right) S_{i j}^{t}-\frac{\alpha_{i j}^{1, t-\Delta t}}{A^{1}}\right]\right\} \\
& \times\left\{\frac{d A^{1}}{d \Delta \varepsilon_{e}^{p, t}}\left(1+C^{1} C^{2}\left(\frac{\Delta \varepsilon_{e}^{p, t}}{A^{1} \sigma_{y}^{0}}\right)^{2}\right)-\frac{2 C^{1} C^{2}}{A^{1}\left(\sigma_{y}^{0}\right)^{2}} \Delta \varepsilon_{e}^{p, t}\right\}
\end{aligned}
$$

and $B$ is given by

$$
B=A^{2}-\frac{C^{1} C^{2}}{A^{1}}\left(\frac{\Delta \varepsilon_{e}^{p, t}}{\sigma_{y}^{0}}\right)^{2}
$$

The material's Jacobian matrix is required for each time increment. The Jacobian matrix for the viscoelastic-plastic model is

$$
\frac{\partial \Delta \varepsilon_{i j}^{t}}{\partial \sigma_{k l}^{t}}=\frac{\partial \Delta \varepsilon_{i j}^{v e, t}}{\partial \sigma_{k l}^{t}}+\frac{\partial \Delta \varepsilon_{i j}^{p, t}}{\partial \sigma_{k l}^{t}}
$$

The plastic-strain increment can be expressed in terms of the effective strain as

$$
\Delta \varepsilon_{i j}^{p, t}=\frac{3}{2 \sigma_{y}^{0}}\left(S_{i j}^{t}-\alpha_{i j}^{t}\right) \Delta \varepsilon_{e}^{p, t}
$$

Therefore, the derivative of the strain increment with respect to the stress increment can be written as

$$
\frac{\partial \Delta \varepsilon_{i j}^{p, t}}{\partial \sigma_{k l}^{t}}=\frac{\partial \Delta \varepsilon_{i j}^{p, t}}{\partial S_{m n}^{t}}\left(\frac{\partial S_{m n}^{t}}{\partial \sigma_{k l}^{t}}-\frac{\partial \alpha_{m n}^{t}}{\partial \sigma_{k l}^{t}}\right)+\frac{\partial \Delta \varepsilon_{i j}^{p, t}}{\partial \Delta \varepsilon_{e}^{p, t}} \frac{\partial \Delta \varepsilon_{e}^{p, t}}{\partial \sigma_{k l}^{t}}
$$

It should be noted that the above model is three dimensional. Given the high computational cost of the 3D model, and since the scarf and lap shear joints considered here are largely two dimensional, a plane-strain condition was considered. The stress and strain components were reduced according to

$$
\varepsilon_{13}=\varepsilon_{23}=\varepsilon_{33}=\sigma_{13}=\sigma_{23}=0
$$



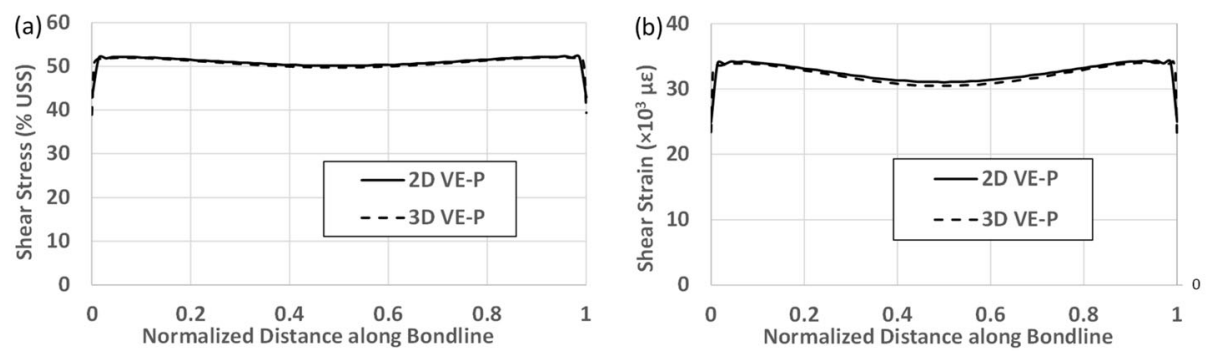

Fig. 9 Comparison of 2D and 3D VE-P models

Fig. 10 Viscoplastic parameters as functions of von Mises stress for the toughened adhesive

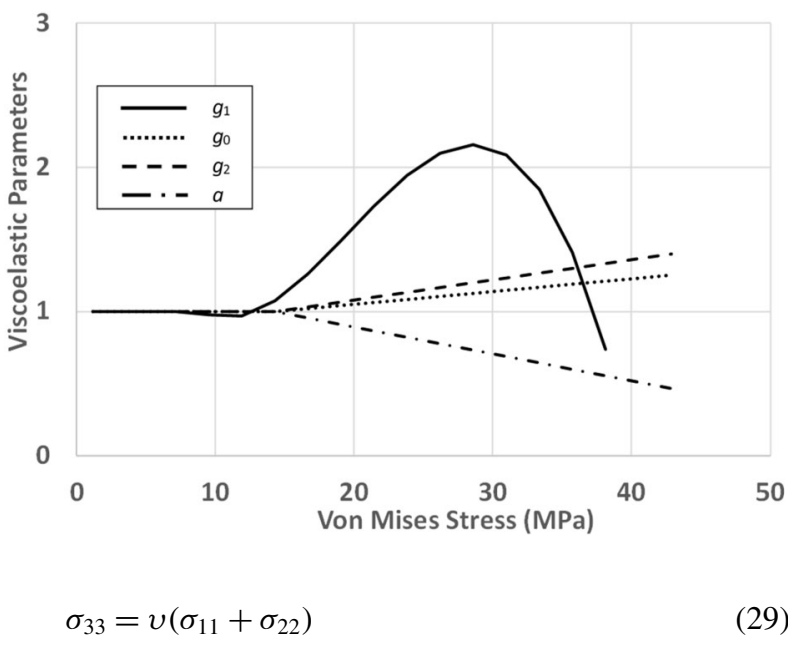

Using the parameters described below, the 2D and 3D models were compared by examining the shear stress and strain along the bondline of the scarf joint at 50\% USS, as shown in Fig. 9. Given the excellent agreement between the models, the 2D model was used in the following.

\section{Model calibration}

The VE-P and VE-VP models shared the same parameters for the viscoelastic component (Chen and Smith 2021), and are presented in Table 1 and Fig. 10. The VE-VP model was developed previously from creep tests with discrete loads, where the viscoelastic parameters describing nonlinearity had a linear dependence on stress. For the cyclic tests with a continuously varying load, the model showed more time dependence than experiment, as shown in Fig. 4a. As nonlinearity was observed to depend strongly on $g_{1}$, a high-order polynomial function was obtained to describe the dependence of $g_{1}$ on stress for both creep and cyclic loading. The dependence of the viscoelastic parameters on stress is presented in Fig. 10.

\subsection{Viscoelastic-plastic model (VE-P)}

The plastic parameters were obtained by fitting its response to a monotonic tensile test of a scarf joint with the toughened adhesive at $148 \mathrm{~N} / \mathrm{s}$ until failure. The viscoelastic-plastic 
Table 1 Parameters in the viscoelastic model for the toughened adhesive

Table 2 Parameters of the viscoelastic-plastic model

Fig. 11 Comparison of the viscoelastic-plastic model to experiment for a monotonically loaded scarf joint

\begin{tabular}{lll}
\hline Prony series & $D_{1}[1 / \mathrm{MPa}]=1.74 \times 10^{-5}$ & $\lambda_{1}[1 / \mathrm{s}]=1 \times 10^{-2}$ \\
$D_{2}[1 / \mathrm{MPa}]=2.32 \times 10^{-5}$ & $\lambda_{2}[1 / \mathrm{s}]=1 \times 10^{-3}$ \\
$D_{3}[1 / \mathrm{MPa}]=1.02 \times 10^{-5}$ & $\lambda_{3}[1 / \mathrm{s}]=5 \times 10^{-4}$ \\
$D_{4}[1 / \mathrm{MPa}]=1.45 \times 10^{-5}$ & $\lambda_{4}[1 / \mathrm{s}]=1 \times 10^{-4}$ \\
$D_{5}[1 / \mathrm{MPa}]=2.9 \times 10^{-5}$ & $\lambda_{5}[1 / \mathrm{s}]=1 \times 10^{-5}$ \\
$J_{0}[1 / \mathrm{MPa}]=1.29 \times 10^{-3}$ & $B_{0}[1 / \mathrm{MPa}]=1.89 \times 10^{-4}$ \\
\hline
\end{tabular}

\begin{tabular}{lllll}
\hline$C^{1}(\mathrm{MPa})$ & $C^{2}(\mathrm{MPa})$ & $\kappa^{1}$ & $\kappa^{2}$ & $\sigma_{y}^{0}(\mathrm{MPa})$ \\
\hline 1516.8 & 82.7 & 82 & 3 & 35 \\
\hline
\end{tabular}

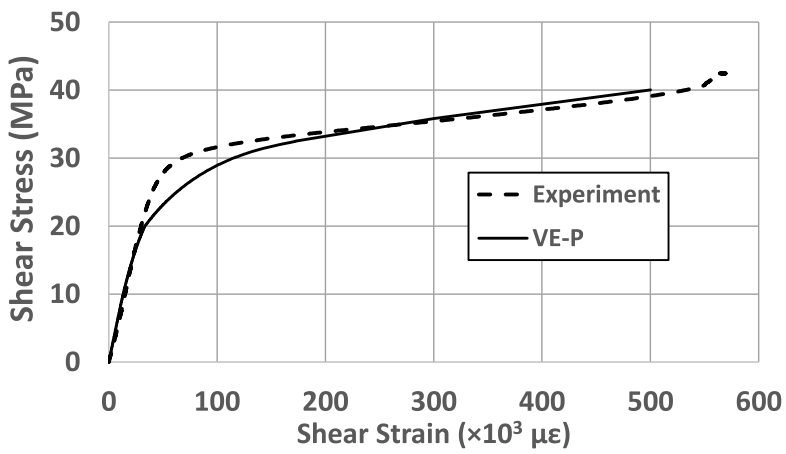

model with von Mises yielding and kinematic hardening was fit to experiment to obtain the plastic parameters shown in Table 2. Figure 11 compares the viscoelastic-plastic model with experiment, showing favorable agreement. It should be noted that the parameters also worked for the elastic-plastic model matching the experimental data to obtain $\beta_{1}$ and $\beta_{2}$ in Eq. (1).

\subsection{Viscoelastic-viscoplastic model (VE-VP)}

Viscoplastic response was described using Perzyna's viscoplastic model (Perzyna 1966), which is written as

$$
\dot{\varepsilon}_{i j}^{v p, t}=\dot{\lambda} m_{i j}=\eta\left\langle\left(\frac{f}{\sigma_{y}^{0}}\right)^{N}\right\rangle \frac{\partial f}{\partial \sigma_{i j}^{t}}
$$

where $\langle x\rangle$ is the McCauley bracket defined as $\langle x\rangle=\max \{0, x\} . \eta$ is a viscosity parameter, and $N$ is a rate-sensitive constant.

Fitting the predicted residual strains (Eq. (30)) to experiment (Fig. 6) would consume significant computational time given the small time increment needed for cyclic loading. Therefore, an alternative approach to obtaining the cyclic viscoplastic strain was investigated. Figure 12 compares the cyclic viscoplastic strain at 50\% USS as a function of time for two frequencies. Their response is indistinguishable, forming a cyclic master curve. Accordingly, the viscoplastic strain for cyclic loading was obtained from the corresponding viscoplastic strain from creep loading (the dashed lines in Fig. 12). With the creep time for 
Fig. 12 Comparison of the viscoplastic strain from creep and cyclic loading at $50 \%$ USS, illustrating the viscoplastic transfer function to obtain cyclic strain from creep response

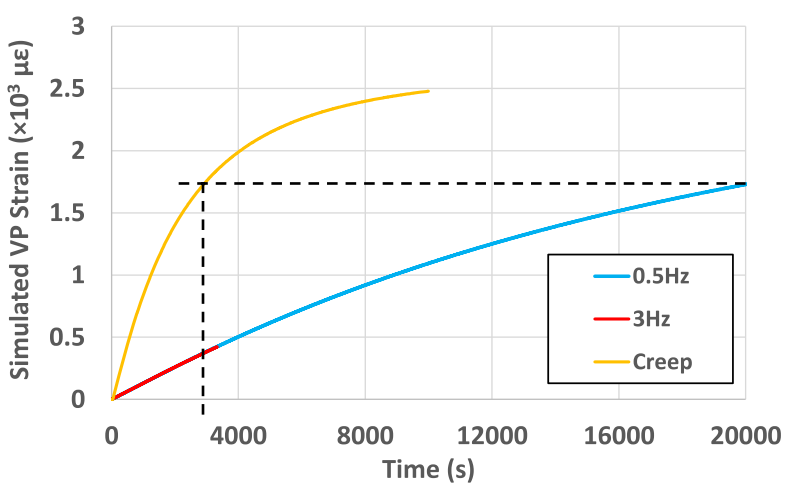

Fig. 13 Fitting of residual strain for the toughened adhesive (error bars represent one standard deviation)

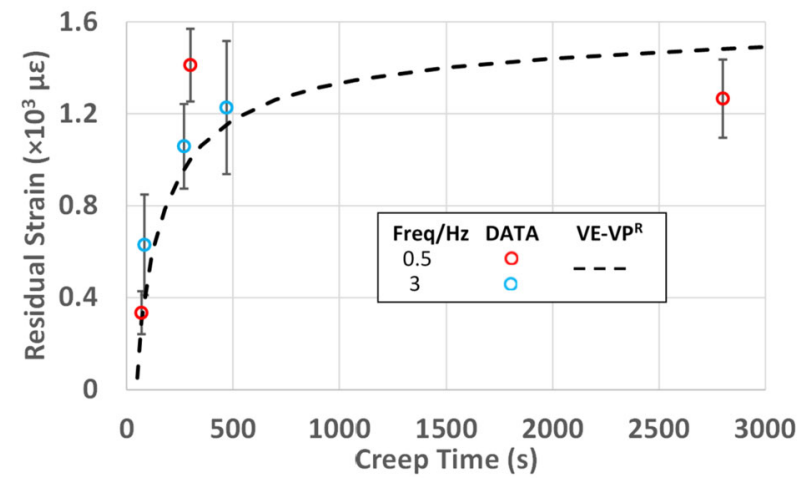

Table 3 A comparison of the viscoplastic coefficients $\eta$ and $N$

\begin{tabular}{lll}
\hline & $\eta$ & $N$ \\
\hline Creep (VE-VP) & $5.5 \times 10^{-5}$ & 1.37 \\
Cyclic (VE-VPR) & 0.07 & 2.4 \\
\hline
\end{tabular}

each cyclic load, the residual strains (averaged for each duration and frequency from Fig. 6) are plotted as a function of creep time in Fig. 13. The parameters $\eta$ and $N$ were found by fitting the simulated residual strain with a 50\% USS creep load (dashed line) to the data. The viscoplastic coefficients from the previous (creep) (Chen and Smith 2021) and present (cyclic) work are compared in Table 3. In the following, to distinguish between the two viscoplastic models, $\mathrm{VE}-\mathrm{VP}^{\mathrm{R}}$ is used to denote the parameters calibrated from the residual strain of cyclic tests.

\section{Numerical results and comparisons}

\subsection{Comparison between VE-VPR and VE-P}

The VE-P and VE-VPR ratcheting-recovery behavior of the toughened adhesive is compared with experiments at $0.5,3$, and $5 \mathrm{~Hz}$ in Figs. 14a-c. In comparison to Fig. 4 and the VE-VP, the VE-VPR had a more favorable agreement with experiment in both the loading 

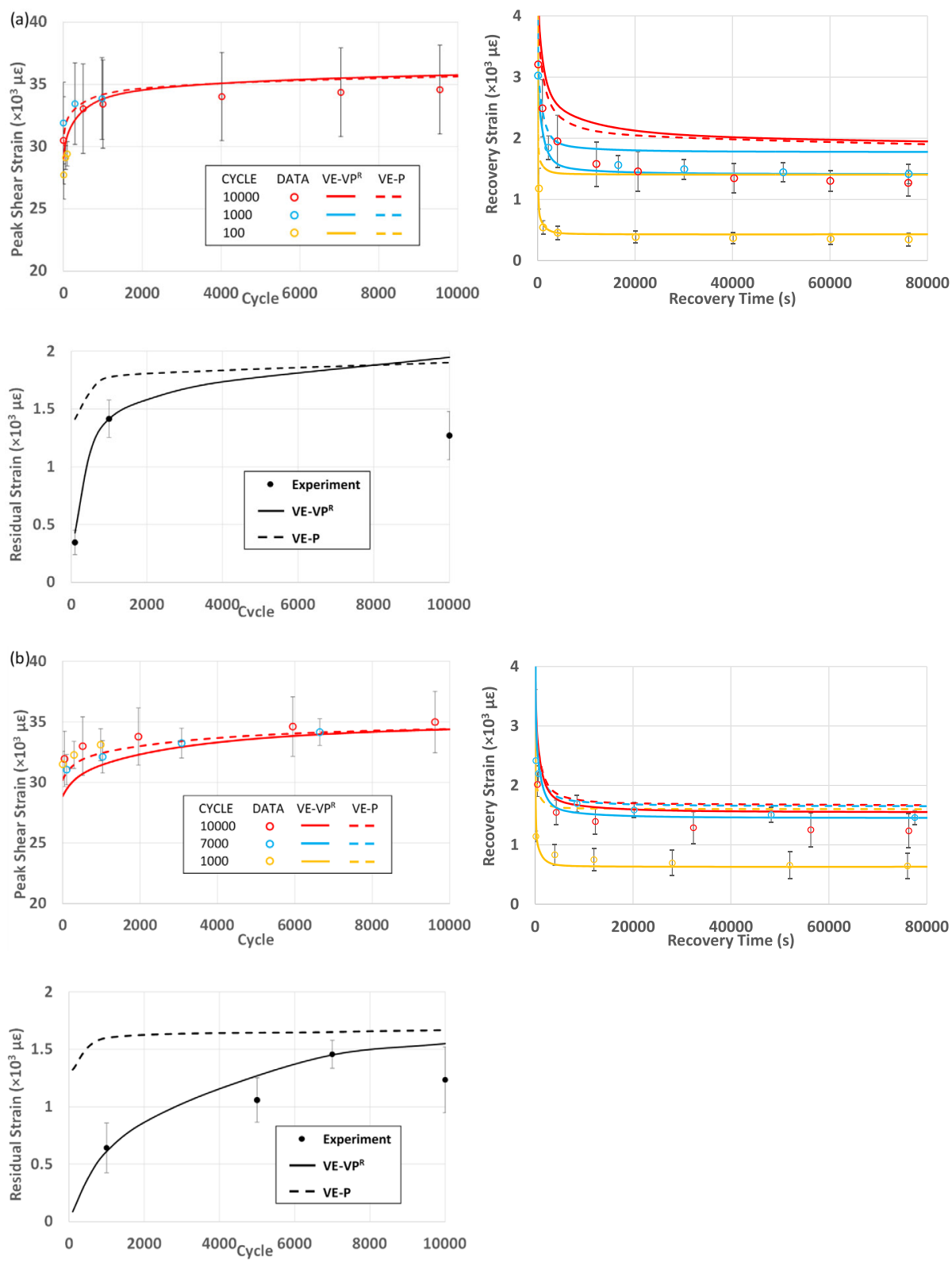

Fig. 14 Comparison of the ratcheting-recovery behavior for the toughened adhesive at (a) $0.5 \mathrm{~Hz}$, (b) $3 \mathrm{~Hz}$, and (c) $5 \mathrm{~Hz}$. Error bars correspond to one standard deviation

and recovery stages. The peak cyclic strain of the VE-P model also agreed with experiment. The experimental residual strain after $80000 \mathrm{~s}$ of recovery is also included in Fig. 14. The residual strain of the $\mathrm{VE}-\mathrm{VP}^{\mathrm{R}}$ showed sensitivity to the number of cycles that was in line with the experimental data. The VE-P model showed favorable agreement with experiment for longer time scales but overestimated the residual strain at shorter durations. This implies 

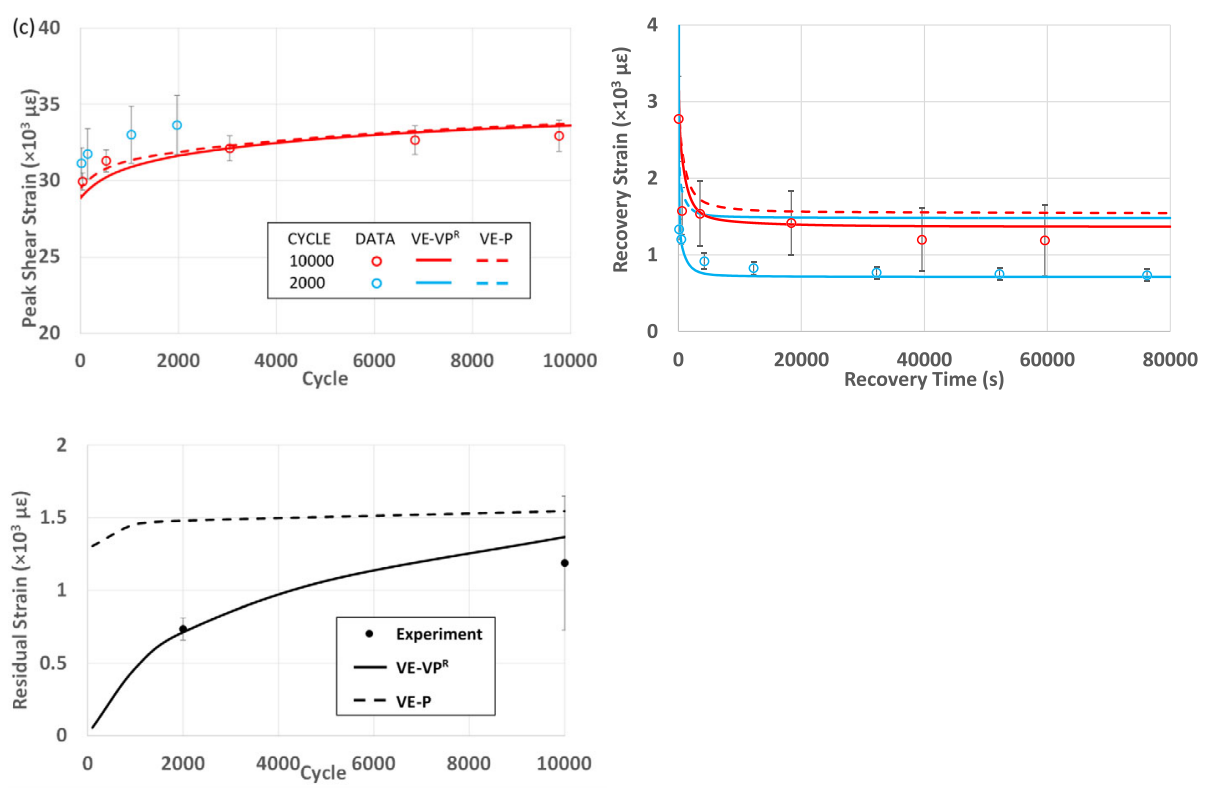

Fig. 14 (Continued)

that viscoplastic effects are more important at shorter durations. While the tests considered here are of relatively short durations ( $<10000$ cycles), it is noteworthy that tests at $0.5,3$ and $5 \mathrm{~Hz}$ all exhibited a similar residual strain of 1300 microstrain. This is consistent with shakedown behavior, where viscoplastic response diminishes at longer time scales (AbdelKarim 2005). Testing at longer durations is needed to identify the significance of viscoplastic behavior at longer times scales.

\subsection{Ratcheting recovery of lap shear joints}

The foregoing has considered adhesive response in a nearly pure shear-stress state using scarf joints. The following considers single lap shear tests to evaluate the model under a more complex stress state. Since viscoplastic response is of interest, only short duration tests were considered (100 to 300 cycles) and the VE-P model was not included in the comparison. The VE-VPR model is compared with experiment in Fig. 15 at 0.5 and $3 \mathrm{~Hz}$. The model showed good agreement with experiment during the loading and recovery stages, including higher strain at the edge of the bond line. (While not included in Fig. 14 for clarity, the VE-VP model reported almost full recovery for these tests.)

Figure 16 shows the simulated shear viscoplastic strain along the midoverlap after 100 cycles' load at $0.5 \mathrm{~Hz}$. The viscoplastic deformation at the edge, rather than the center, caused residual stress in the adhesive and consequently induced residual strain near the center ( $3 \mathrm{~Hz}-\mathrm{C}$ and $0.5 \mathrm{~Hz}-\mathrm{C}$ in Fig. 15, and the dotted line in Fig. 16). The absence of viscoplastic deformation near the overlap center indicated that ratcheting near the center was viscoelastic. 

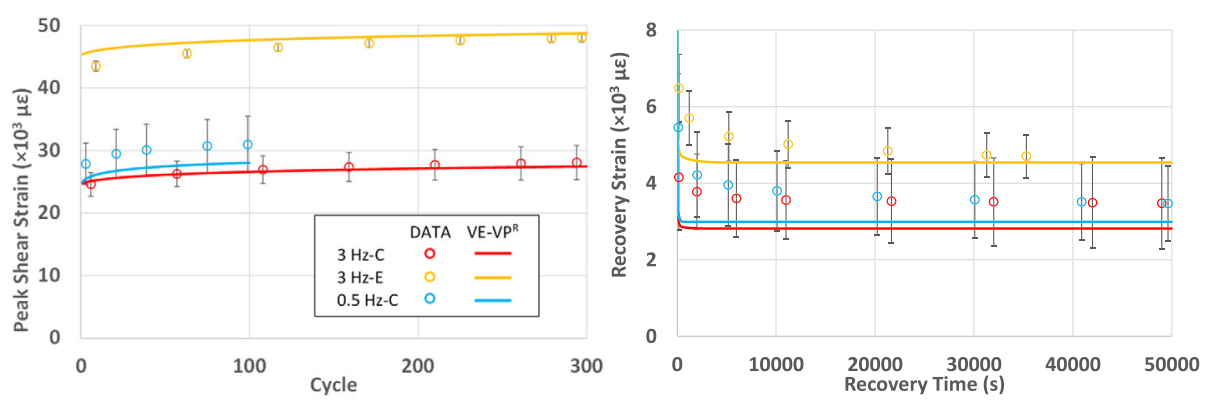

Fig. 15 Comparisons of ratcheting-recovery responses near the center and edge of the overlap between the strain gages and VE-VP, VE-VPR models. $\mathrm{C}$ and $\mathrm{E}$ denote the center and edge area, respectively. Error bars correspond to one standard deviation

Fig. 16 Shear viscoplastic and residual strain along the lap shear overlap under cyclic load at $0.5 \mathrm{~Hz}$ and 100 cycles

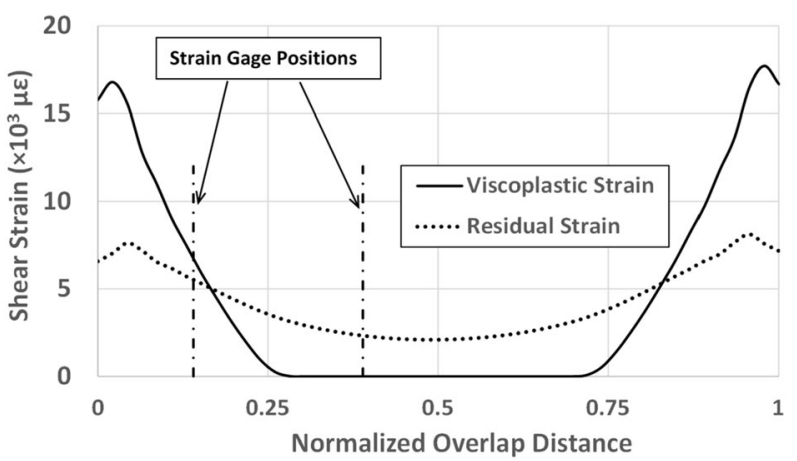

\section{Conclusion}

This work considered the ratcheting-recover behavior of a standard and a toughened adhesive. Using a VE-VP model from creep behavior in prior work, the response of a toughened adhesive exhibited less time dependence at longer time scales and more residual strain at shorter time scales than was predicted. Failure surfaces of adhesives subjected to creep and cyclic loads showed that voids might accelerate the toughened adhesive's failure under cyclic load and alter its viscoplastic response. Accordingly, a VE-VPR model was calibrated with the residual strain from cyclic loading. A VE-P model was also proposed as an alternative means of reducing the time dependence. The models were compared using the ratcheting-recovery behavior of a toughened adhesive and scarf joints. The $\mathrm{VE}-\mathrm{VP}^{\mathrm{R}}$ model had good agreement with experiment for describing permanent strain evolution at varying frequencies and time scales. The VE-P model only agreed well for high cycles counts. The $\mathrm{VE}-\mathrm{VP}^{\mathrm{R}}$ model also described the ratcheting-behavior of lap shear joints. The model had good agreement with strain measurements near the center and edge of the overlap. The viscoplastic deformation in the lap shear joint only occurred near the overlap edge, so that ratcheting near the center was viscoelastic.

Open Access This article is licensed under a Creative Commons Attribution 4.0 International License, which permits use, sharing, adaptation, distribution and reproduction in any medium or format, as long as you give appropriate credit to the original author(s) and the source, provide a link to the Creative Commons licence, and indicate if changes were made. The images or other third party material in this article are included in the 
article's Creative Commons licence, unless indicated otherwise in a credit line to the material. If material is not included in the article's Creative Commons licence and your intended use is not permitted by statutory regulation or exceeds the permitted use, you will need to obtain permission directly from the copyright holder. To view a copy of this licence, visit http://creativecommons.org/licenses/by/4.0/.

\section{References}

Abdel-Karim, M.: Shakedown of complex structures according to various hardening rules. Int. J. Press. Vessels Piping 82, 427-458 (2005)

ASTM D3165-07: Standard Test Method for Strength Properties of Adhesives in Shear by Tension Loading of Single-Lap-Joint Laminated Assemblies. ASTM International, West Conshohocken (2014)

Broughton, W.R.: Project PAJ3-Combined cyclic loading and hostile environments 1996-1999. Report no 19. Project PAJ3 (1999)

Broughton, W.R., Mera, R.D., Hinopoulos, G.: Cyclic Fatigue Testing of Adhesive Joints Test Method Assessment. Environments (1999)

Chen, Y., Smith, L.V.: A nonlinear viscoelastic-viscoplastic constitutive model for adhesives under creep. Mech. Time-Depend. Mater. 25, 565-579 (2021)

Da Costa Mattos, H.S., Martins, S.D.A.: Plastic behaviour of an epoxy polymer under cyclic tension. Polym. Test. 32, 1-8 (2013)

da Costa Mattos, H.S., et al.: Analysis of the cyclic tensile behaviour of an elasto-viscoplastic polyamide. Polym. Test. 58, 40-47 (2017)

Da Silva, L.F.M., Adams, R.D., Gibbs, M.: Manufacture of adhesive joints and bulk specimens with hightemperature adhesives. Int. J. Adhes. Adhes. 24, 69-83 (2004)

Fessel, G., Broughton, J.G., Fellows, N.A., Durodola, J.F., Hutchinson, A.R.: Evaluation of different lap-shear joint geometries for automotive applications. Int. J. Adhes. Adhes. 27, 574-583 (2007)

Frederick, C., Armstrong, P.: A mathematical represemtation of the mulitiaxial Bauschinger effect. Mater. High Temp. 24, 1-26 (2007)

Groth, H.L.: Viscoelastic and viscoplastic stress analysis of adhesive joints. Int. J. Adhes. Adhes. 10, 207-213 (1990)

He, D., Sawa, T., Iwamoto, T., Hirayama, Y.: Stress analysis and strength evaluation of scarf adhesive joints subjected to static tensile loadings. Int. J. Adhes. Adhes. 30, 387-392 (2010)

Krause, M., Smith, L.V.: Ratcheting in structural adhesives. Polym. Test. 97, 107154 (2021)

Lai, J., Bakker, A.: 3-D schapery representation for non-linear viscoelasticity and finite element implementation. Comput. Mech. 18, 182-191 (1996)

Li, G., Lee-Sullivan, P.: Finite element and experimental studies on single-lap balanced joints in tension. Int. J. Adhes. Adhes. 21, 211-220 (2001)

Lin, Y.C., Chen, X.-M., Zhang, J.: Uniaxial ratchetting behavior of anisotropic conductive adhesive film under cyclic tension. Polym. Test. 30, 8-15 (2011)

Mardani, H., Stein, N., Rosendahl, P.L., Becker, W.: An efficient stress and deformation model for arbitrary elastic-perfectly plastic adhesive lap joints. Int. J. Adhes. Adhes. 103, 102679 (2020)

Micro-Measurements, V.: Strain gage rosettes: selection, application and data reduction. Tech. Note TN 515 , 151-161 (2008)

Mohapatra, P.C., Smith, L.V.: Characterization of adhesive yield criteria using mixed-mode loading. J. Adhes. Sci. Technol. 33, 1248-1260 (2019a)

Mohapatra, P.C., Smith, L.V.: Characterization of adhesive yield criteria usingmixed-mode loading. J. Adhes. Sci. Technol. 33, 1248-1260 (2019b)

Mohapatra, P.C., Smith, L.V.: Adhesive hardening and plasticity in bonded joints. Int. J. Adhes. Adhes. 106, $102821(2021)$

Motta, E.P., Reis, J.M.L., da Costa Mattos, H.S.: Analysis of the cyclic tensile behaviour of an elastoviscoplastic polyvinylidene fluoride (PVDF). Polym. Test. 67, 503-512 (2018)

Motta, E.P., Reis, J.M.L., da Costa Mattos, H.S.: Modelling the cyclic elasto-viscoplastic behaviour of polymers. Polym. Test. 78, 105991 (2019)

Pandey, P.C., Narasimhan, S.: Three-dimensional nonlinear analysis of adhesively bonded lap joints considering viscoplasticity in adhesives. Comput. Struct. 79, 769-783 (2001)

Pandey, P.C., Shankaragouda, H., Singh, A.K.: Nonlinear analysis of adhesively bonded lap joints considering viscoplasticity in adhesives. Comput. Struct. 70, 387-413 (1999)

Perzyna, P.: Fundamental problems in viscoplasticity. In: Advances in Applied Mechanics, vol. 9, pp. 243-377. Elsevier, Amsterdam (1966) 
Sayman, O.: Elasto-plastic stress analysis in an adhesively bonded single-lap joint. Composites, Part B, Eng. 43, 204-209 (2012)

Shariati, M., Hatami, H., Yarahmadi, H., Eipakchi, H.R.: An experimental study on the ratcheting and fatigue behavior of polyacetal under uniaxial cyclic loading. Mater. Des. 34, 302-312 (2012)

Shen, X., Xia, Z., Ellyin, F.: Cyclic deformation behavior of an epoxy polymer. Part I: experimental investigation. Polym. Eng. Sci. 44, 2240-2246 (2004)

Tao, G., Xia, Z.: Ratcheting behavior of an epoxy polymer and its effect on fatigue life. Polym. Test. 26, 451-460 (2007)

Teixeira de Freitas, S., Sinke, J.: Failure analysis of adhesively-bonded skin-to-stiffener joints: metal-metal vs. composite-metal. Eng. Fail. Anal. 56, 2-13 (2015)

Xia, Z., Shen, X., Ellyin, F.: Cyclic deformation behavior of an epoxy polymer. Part II: predictions of viscoelastic constitutive models. Polym. Eng. Sci. 45, 103-113 (2005)

Zehsaz, M., Vakili-Tahami, F., Saeimi-Sadigh, M.A.: Parametric study of the creep failure of double lap adhesively bonded joints. Mater. Des. 64, 520-526 (2014)

Zhang, J., Li, H., Li, H.Y., Wei, X.L.: Uniaxial ratchetting and low-cycle fatigue failure behaviors of adhesively bonded butt-joints under cyclic tension deformation. Int. J. Adhes. Adhes. 95, 102399 (2019)

Publisher's Note Springer Nature remains neutral with regard to jurisdictional claims in published maps and institutional affiliations. 